\title{
3.2. ПРИМЕНЕНИЕ ТЕОРИИ СИСТЕМ ЛИНЕЙНЫХ НЕРАВЕНСТВ В ПРОГНОЗНОМ АНАЛИЗЕ ФИНАНСОВОЙ УСТОЙЧИВОСТИ КОММЕРЧЕСКОЙ ОРГАНИЗАЦИИ
}

Негашев Е.В., к.э.н., доцент,

Департамент учета, анализа и аудита

ФГОБУ ВО «Финансовый университет при Правительстве РФ», г. Москва

В статье, продолжающей изложение методики анализа финансовой устойчивости коммерческой организации в рамках новой парадигмы анализа, рассмотрены возможности применения в прогнозном анализе линейных неравенств, ограничивающих стоимостные величины хозяйственных операций, восстанавливающих финансовое равновесие, в качестве тестов для сравнения различных сценариев будущих хозяйственных операций и в качестве инструмента построения возможных сценариев восстановления финансового равновесия в виде решений систем линейных уравнений и неравенств. На численном примере демонстрируется алгоритм внутренних точек для решения таких систем.

\section{Литература}

1. Зоркальцев В.И. Системы линейных неравенств [Текст] : учеб. пособие / В.И. Зоркальцев, М.А. Киселева - Иркутск : Изд-во Иркутского гос. ун-та, 2007. -128 с.

2. Негашев Е.В. Аналитическое моделирование финансового состояния компании [Текст] : монография / Е.В. Негашев. М. : ИНФРА-М, 2013. - 186 с. - (Научная мысль) - DOI 10.12737/1641.

3. Негашев Е.В. Логическое обоснование новой парадигмы анализа финансовой устойчивости коммерческой организации на основе концепции устойчивости равновесного состояния системы [Текст] / Е.В. Негашев // Аудит и финансовый анализ. - 2018. - №2. - С. 90-98.

4. Негашев Е.В. Методика анализа финансовой устойчивости коммерческой организации, построенная в рамках новой парадигмы анализа [Текст] / Е.В. Негашев // Аудит и финансовый анализ. - 2018. - №6. - С. 32-44.

5. Негашев Е.В. Методика построения линейных ограничений для стоимостных величин хозяйственных операций, восстанавливающих фринансовое равновесие коммерческой организации [Текст] / Е.В. Негашев // Аудит и фринансовый анализ. - 2019. - №3. - С. 46-55.

6. Черников С.Н. Линейные неравенства [Текст] / С.Н. Черников. - М. : Наука, 1968. - 488 с.

\section{Ключевые слова}

Балансовая модель фринансового состояния; критериальная функция финансового состояния; канонический вид критериальной функции; финансовое равновесие; матрицы влияния хозяйственных операций на актив и пассив балансовой модели; вектор хозяйственных операций; восстановление фринансового равновесия; тестирование сценариев будущих хозяйственных операций; система линейных неравенств и уравнений; алгоритм внутренних точек.

\section{Негашев Евгений Владимирович}

\section{РЕЦЕНЗИЯ}

Актуальность темы. Необходимость повышения качества прогнозного анализа финансовой устойчивости коммерческих организаций сегодня для всех очевидна. Е.В. Негашев систематически работает над решением этой проблемы. В своих предыдущих статьях он предложил построение новой парадигмы анализа финансовой устойчивости, основанной на современной теории систем, рассматривал алгоритмы прогнозного анализа финансовой устойчивости, позволявшие оценить возможности восстановления финансового равновесия в прогнозном периоде. Эти алгоритмы включали построение линейных неравенств, ограничивающих стоимостные величины возможных будущих хозяйственных операций, восстанавливающих финансовое равновесие.

Актуальность представленной к публикации работы определяется потребностью в разработке методики формирования допустимых сценариев будущих хозяйственных операций, восстанавливающих финансовое равновесие, с помощью решения линейных ограничений методами современной теории систем линейных неравенств.

Научная новизна и практическая значимость. В статье изложены алгоритмы решения линейных неравенств, ограничивающих стоимостные величины хозяйственных операций, восстанавливающих финансовое равновесие, для случаев наиболее распространенных критериальных функций финансового равновесия.

Предлагаемая методика формирования допустимых сценариев будущих хозяйственных операций использует алгоритм внутренних точек для решения систем линейных неравенств, упрощенный с помощью дополнительных ограничений на стоимостные величины хозяйственных операций.

Практическая значимость предлагаемой методики заключается в возможности использования формируемых сценариев восстановления финансового равновесия в процедурах обоснования решений по управлению финансовой устойчивостью коммерческой организации. В качестве пожелания для будущих публикаций можно рекомендовать лишь более наглядные иллюстрации возможностей практического применения разработок автора в финансовом анализе на реальных примерах отечественных предприятий.

Заключение. Рецензируемая статья отвечает требованиям, предъявляемым к научным публикациям, и может быть рекомендована к опубликованию

Бариленко В.И., д.э.н., профессор Департамента учета, анализа и аудита ФГОБУ ВО «Финансовый университет при Правительстве РФ», г. Москва.

DOI 10.38097/AFA.2020.64.54.007 